\title{
JUURNAL.RU
}

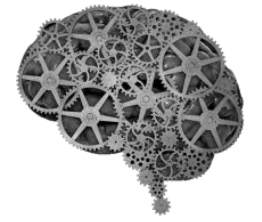

COMPANY GROUP "INTELLEKT"

\author{
Митряйкин В.И., Зайцева Т.А. \\ Казанский национальный исследовательский технический университет \\ им.А.Н.Туполева-КАИ \\ Казань, Россия
}

doi: 10.18411/lj2016-9-1-10

idsp 000001: lj2016-18-1-10

\section{Усовершенствование метода спиральной компьютерной томографии для инденфикации механических характеристик композитных и биологических материалов при расчете системы "Имплант-кость"}

Важнейшими достижениями современной травматологии и ортопедии является создание и внедрение имплантов для укрепления или замены пораженных органов. Главным качеством имплата должна быть безвредность, а для имплантов, применяющихся при лечении опорно-двигательного аппарата еще и прочность.Дегенеративно-дистрофические поражения крупных суставов относятся к числу самых распространенных заболеваний. По данным официальной статистики, среди обратившихся за помощью по поводу болезней костно-мышечной системы в РФ больные деформирующим остеоартрозом составили 21\%. При этом в структуре указанной патологии дегенеративнодистрофические заболевания тазобедренного сустава (ТБС) занимают около $50 \%$.

Эндопротезирование тазобедренного сустава является одним из высокотехнологических оперативных вмешательств. Потребность операции эндопротезирования в России составляет не менее 250 тысяч в год, а выполняется примерно 85 тысяч. Количество осложнений, сопровождающих эту операцию, остается достаточно высоким. В общей структуре осложнений наиболее частыми, тревожными и проблематичными для лечения являются вывихи эндопротеза и разрушение бедренной кости.

В литературе активно обсуждают факторы, способствующие возникновению вывихов, однако единого мнения о влиянии каждого фактора на 
частоту вывихов, на данный момент отсутствует. В настоящее время разработаны некоторые критерии для расчета прогнозируемой долговечности эндопротезов, рассмотрим один из них, приведенный в работе.

Предлагается для оценки надежности системы “эндопротез-кость” применять зависимость:

$$
R_{0}=\prod_{i} R_{i}
$$

где $R_{1}$ - надежность устойчивой фиксации чашки эндопротеза, $R_{2}$ надежность изостойкости поверхности, $R_{3}$ - надежность несущей способности тазовой кости, $R_{4-}$ надежность несущей способности сохраненной части бедренной кости, $R_{5}$ - надежность несущей способности костного цемента, $R_{6}$ надежность соблюдения больным предписанного режима и т.д.

Если принять во внимание хотя бы только четыре из этих факторов с надежностью каждого на уровне 97,5\%, то, иными словами, каждого десятого пациента ожидают серьезные осложнения с угрозой удаления или замены эндопротеза.

Анализ приведенных факторов рассматриваемой биомеханической системы "эндопротез-кость" показывает, что важное место в повышении её надежности занимают механические характеристики кости и эндопротеза. Прочность кости (механические свойства) обеспечивается физико-химическим единством органических и неорганических веществ, а также конструкцией костной ткани. Костная ткань состоит из губчатой, кортикальной и субходральной частей. Каждая из этих частей обладает индивидуальной структурой и свойствами. Для травматологов и ортопедов наиболее важными свойствами кости является ее прочность и жесткость. Эти и другие характеристики лучше всего могут быть понятны для кости или другого материала изучением его поведения при нагрузке растяжения, сжатия, изгиба и т.д. В реальной жизни провести прямые измерения достаточно сложно.

Значения модуля упругости Е и коэффициента Пуассона $\mu$, для материалов эндопротеза и костных структур тазобедренного сустава приведены в таблице 1. 
Таблиияа

\begin{tabular}{|c|c|c|}
\hline Материал & Е ,МПа & $\mu$ \\
\hline \multicolumn{2}{|c|}{ ТБС } & 0,3 \\
\hline Кортикальный слой & 15000 & 0,2 \\
\hline Субхондральный слой & 3000 & 0,3 \\
\hline Губчатая кость & 1000 & 0,3 \\
\hline \multicolumn{2}{|c|}{ Эндопротез } \\
\hline Сплав ВТ16 & 115000 & 0,19 \\
\hline Керамика & 70000 & \\
\hline
\end{tabular}

Анализ этих характеристик показывает, что модуль упругости эндопротеза в 10-15 раз выше модуля упругости кости, что может привести к расшатыванию эндопротеза или разрушению костной ткани.

Изучение поведения механических характеристик системы “эндопротезкость" выявило необходимость внедрения новых биоматериалов, которые обладали бы высокой прочностью со значением модуля упругости близким к величине живой ткани. Эта задача решается на основе использования современных композиционных материалов. Композиционные материалы уже используются в конструкции эндопротеза в виде пар трения.

Проблема прочности системы “имплант-кость" в настоящее время является актуальной задачей. Она может достаточно успешно решается с помощью современных методов, расчетов, например, методом конечных элементов. Создание математических моделей для этого метода требует подробных данных о структуре и механических свойствах моделируемых объектов.

Механические свойства костной ткани имеют значительный разброс. Они зависят от ряда факторов механической (скорость и продолжительность нагружения, ориентация, форма, размеры образца и т.д.) и биологической природы (пол и возраст, степень активности физиологических функций в костной ткани, вид и степень патологических изменений в кости и др.). Являются и механические характеристики импланта. Поскольку импланты в организме работают в сложных условиях механического нагружения, их механические и химические свойства в изменяются как правило, в сторону ухудшения. Причинами снижения долговечности имплантов является рост трещин под влиянием агрессивной среды организма и вибрационных нагрузок.

Между структурой и механическими свойствами материалов имеется определенная взаимосвязь, которая позволяет судить о прочностных 
характеристиках материала по результатам исследования структуры, не прибегая к измерению механических параметров.

Прогнозирование прочности биомеханических материалов с использованием современных методов неразрушающего контроля связано в основном с оценкой косвенной статистической взаимосвязи прочности и физических параметров, измеренных на одних и тех же образцах. После установления эмпирических корреляционных зависимостей на образцах определяют физические параметры по которым судят о прочности костного материала на конкретном участке с установленным имплантом. Коэффициенты корреляции и точность оценки прочности существенно повышаются при использовании нескольких физических параметров.

Одной из основных физических характеристик структуры материала является его плотность $\rho\left(2 / \mathrm{M}^{3}\right)$. Она используется при расчетах большинства физических и механических характеристик материала.

Для композиционных материалов с использованием плотности можно определить динамический модуль упругости, коэффициент теплопроводности, коэффициенты отражения или прохождения упругих и электромагнитных волн.

Механические характеристики костного материала также зависят от плотности. Компрессионная прочность трабекулярной кости $\sigma$ связана с её плотностью степенной эмпирической зависимостью:

$$
\sigma=60 \rho^{2},[\mathrm{M \Pi а}]
$$

а компрессионный модуль упругости Е находится по следующей зависимости по формуле:

$$
E=1,915 \cdot \rho^{3},[\mathrm{M \Pi a}]
$$

Для определения плотности композиционных материалов используются следующие методы: метод непосредственного взвешивания, гидростатический, по паспортным данным, акустический, диэлектрический, радиационный и др.

Для оценки плотности костных структур пациента используют ультразвуковую и лучевую диагностику.

Одним из современных методом неразрушающего контроля является спиральная компьютерная томография, которая объединяет информативные достоинства рентгеновского излучения с последними достижениями науки и 
вычислительной техники, но её применение для определения плотности композиционных материалов и костных структур находятся на стадии разработки.

Первоначальное применение компьютерной томографии было связано с исследованием структуры образцов из различных материалов. Была экспериментально подтверждена возможность отображения внутренней структуры образца по проекциям (или цифровым данным), представляющим интегральное линейное поглощение материалом рентгеновского излучения. Как уже отмечалось, линейный коэффициент ослабления излучения показывает насколько оно снижается при прохождении слоя вещества определённой толщины. В литературе этот коэффициент часто называют «плотностью». Однако надо учитывать, что соотношение между ослаблением излучения и плотностью достаточно неопределённое и требует дополнительных исследований.

Анализ характерных особенностей многих современных композиционных материалов показывает, что метод СКТ не только адекватен задаче контроля конструкций из композиционных материалов, но и обладает значительным запасом методических и метрологических возможностей дальнейшего повышения объёма информации о внутренней структуре подобных изделий. Этому способствуют такие характерные свойства композиционных материалов как относительно низкая плотность, достаточно высокий (в масштабе пороговой чувствительности СКТ) контраст плотности наполнителей (включений) и большой объём априорной информации об элементном составе и средних характеристиках структуры.

Для установления корреляционной зависимости между числами Хаунсвильда (ед. Н) и плотностью исследуемого материала $(\rho)$, использовались образцы, вырезанные из заготовок изготовленных специально с различными сочетаниями связующего и наполнителя, а также образцы имеющие стендовую и эксплуатационную наработку. Определение плотности образцов проводилось по ГОСТ 15139-73 как отношение массы к объёму. Затем образцы исследовались на спиральном компьютерном томографе, определялись числа Хаунсфильда в различных точках образца или вдоль выбранного сечения. На базе проведённых 
исследований строилась корреляционная зависимость между плотностью и числами Хаунсфильда конкретного материала.

Количественная оценка плотности материала с помощью компьютерного томографа основана на разнице в поглощении рентгеновского излучения различными материалами. Значения коэффициентов ослабления для композитных материалов в известной нам литературе отсутствуют. Массовый коэффициент ослабления излучения контролируемого материала $\mu(E)$, при заданном значении энергии рентгеновского излучения Е, является функцией, зависящей от плотности материала $\rho_{n л}$ и его толщины $h$.

$$
\mu(E)=f\left(\rho_{n л} h\right)
$$

При постоянной толщине исследуемой конструкции коэффициент ослабления зависит только от плотности материала $\rho_{n л}$.

Проведенные авторами исследования позволили установить предварительную усредненную зависимость плотности материала от его коэффициента ослабления в ед.Н, определенного на КТ.

В результате этого появляется возможность путем количественной оценки коэффициентов ослабления, полученных при рентгеновском облучении исследуемого объекта, и последующим определением плотности определить

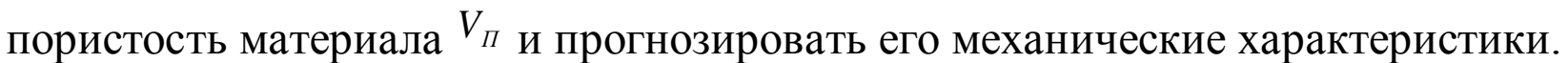

Результаты замеров едНдля композитных материалов и костных структур приведены:
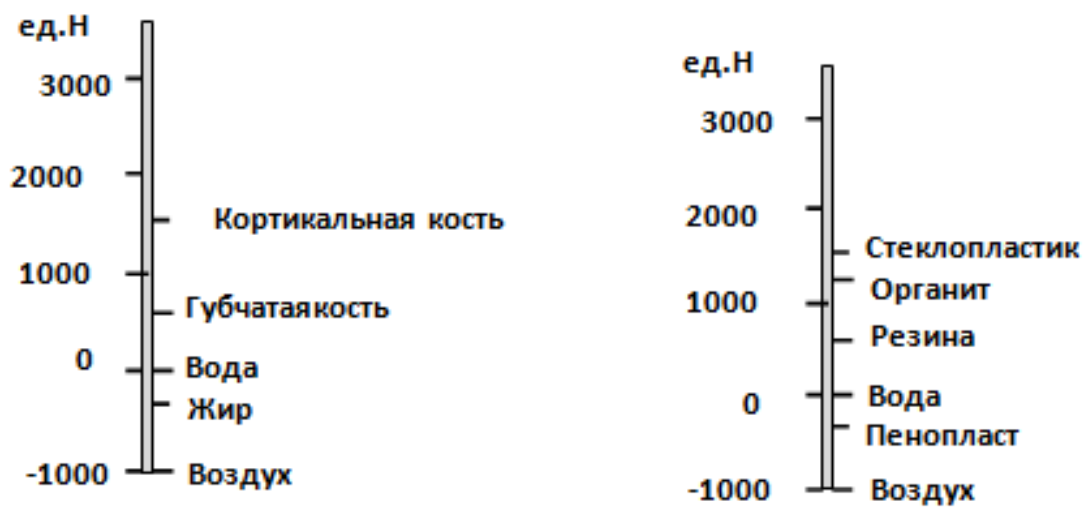

Эти результаты свидетельствуют о том, что импланты изготовленные из композиционных материалов могут быть с достаточной точностью исследоваться вместе с костными структурами. 
Работа выполнена при финансовой поддержки Российского Фонда Фундаментальных Исследований (грант №16-08-00416).

\section{Литература:}

1. Гайсин Р.Р., Закиров Р.Х., Зарипов Р.А., Никифорова А.В., Саченков О.А. Трехмерная реконструкция внутренних органов с одним характерным размером на основе компьютерной томографии. Практическая медицина. 2013. № 1-2-1 (69). C. 22-24.

2. Гайсин Р.Р., Никифорова А.В., Кугуракова В.В., Саченков О.А. Трехмерная платформонезависящая визуализация данных томографии. Научно-технический вестник Поволжья. 2013. № 4. С. 137-139.

3. Коноплев Ю.Г., Мазуренко А.В., Саченков О.А., Тихилов Р.М. Численное исследование влияния степени недопокрытия вертлужного компонента на несущую способность эндопротеза тазобедренного сустава. Российский журнал биомеханики. 2015. Т. 19. № 4. С. 330-343.

4. Митряйкина Е.В., ЗайцеваТ.А. Внедрение спиральной комьютерной томографии для определения механических характеристик материала путем исследования его внутренней структуры. Научно-технический вестник Поволжья. №6 2012г. - Казань: Научно-технический вестник Поволжья, 2012. - 498 с.

5. Хасанов Р.Ф., Андреев А.П., Скворцов А.П., Саченков О.А., Яшина И.В. Биомеханическое обоснование хирургического лечения болезни Легг Кальве - Пертеса. Практическая медицина. 2015. № 4-1. С. 200-203. 